\title{
Application of Groupthink to Generation Y Decision Making Processes within a Professional Services Context in New Zealand
}

\author{
David $\operatorname{Hogg}^{1}$ \\ ${ }^{1}$ Auckland University of Technology, Auckland, New Zealand \\ Correspondence: David Hogg, Private Bag 115033, Auckland 1140, New Zealand. Tel: 64-9-303-0741. E-mail: \\ dlhno1@hotmail.com
}

Received: December 19, 2012 Accepted: March 8, 2012 Online Published: March 22, 2013

doi:10.5539/ijbm.v8n8p69

URL: http://dx.doi.org/10.5539/ijbm.v8n8p69

\begin{abstract}
Many organisations are adjusting to the presence of Generation $\mathrm{Y}$ and their values. Industries that have large annual intakes of employees, like Professional Services, find this adjustment particularly challenging. Generation Y challenges workplace rules and norms, this article seeks to understand the decision making process used by Generation Y to form expectations and perceptions in relation to workplace rules and norms. Understanding this process will help organisations to better educate and influence Generation Y regarding their career choices and conduct within the workplace. This article will focus on applying the Groupthink theory to explain the decision making process used by Generation $Y$ to form expectations and perceptions in relation to workplace rules and norms. In the conclusion an adjusted Groupthink Model that applies specifically to this context is presented. Lessons for organisations that may want to have greater influence over the decision making process used by Generation $\mathrm{Y}$ are also presented.
\end{abstract}

Keywords: Groupthink, Generation Y, decision making, antecedents, workplace perceptions, ubiquitous

\section{Introduction}

Many organisations are adjusting to the presence of Generation $\mathrm{Y}$ and their associated values in the workplace. This adjustment is not easy, as older generations in the workplace are confronted with a differing and sometimes opposing sets of values. While many organisations have pockets of it to manage, industries that have large annual intakes of employees, like Professional Services (e.g. accounting and law firms) have to manage Generation $Y$ employees on a large scale.

Managing Generation $\mathrm{Y}$ is challenging, many managers have expressed frustration at the demands and expectations of Generation $\mathrm{Y}$ employees. This frustration is intensified in environments like Professional Services, where the business model used means a large number of Generation Y employees commence as graduates every year. This article focuses in particular on the decision making process used by Generation $\mathrm{Y}$ to form expectations and perceptions in relation to workplace rules and norms.

Anecdotally, Generation Y makes decisions in the workplace regarding time to promotion or fair remuneration by comparing themselves against their peers. This is particularly interesting when the current literature expressly states that Generation Y employees are defined by; wanting independence, wanting to be treated as equals, wanting customised personal development and being selfish. There must be a process that leads individuals of Generation $\mathrm{Y}$ to develop expectations that are in contradiction with the literature. A central point of contradiction is the lack of consideration of their own (or their peers) personal circumstances that may have resulted in the differentiation made by employers amongst Generation Y employees.

Groupthink Theory is applied to explain the decision making process used by Generation $\mathrm{Y}$ to form expectations and perceptions in relation to workplace rules and norms. The result of which is the anecdotal evidence of decisions being made by comparing themselves to other Generation Y employees. The theory of Groupthink indicates the environment and context within which Groupthink takes place contributes to the process of Groupthink. This article will focus on applying the process of Groupthink to Generation Y employees in the Professional Services industry, though this article could apply to any industry that has large annual intakes of employees from tertiary institutions. The following is an outline of the pertinent facts about the Professional Services industry and Generation Y (the environment and context). 
This issue of decision making is worth investigating as a large proportion of Professional Services Firms are made up of younger and newer employees. The effect they have on the morale, culture and performance of the firm is profound. Therefore understanding this dynamic will help organisations to better educate and influence Generation Y regarding their career choices and conduct within the workplace.

\section{Methodology}

The methodological approach used in this article is a mixture of meta-analysis, observation and anecdotal evidence. First, the structure of Professional Service Firms and their dependence is discussed using observational evidence. Second, a meta-analysis of the literature on Generation $\mathrm{Y}$ is undertaken to establish key behaviours and values. Third, a meta-analysis of the literature regarding the validity of the Groupthink Model, specifically focusing on the Antecedents of the Groupthink Model as they are the strongest precursor to the occurrence of Groupthink, is undertaken. Fourth, each of the Antecedents are applied to Generation Y employees and the Professional Services Environment. Fifth, the Symptoms and Defects of the Groupthink Model are applied to anecdotal and observed behaviours of Generation Y employees in a Professional Services Environment. Finally, lessons for organisations are offered followed by an emended model of Groupthink that fits this specific situation.

\section{Professional Services Industry}

Professional Services operate a unique business model. Professional Services are one of few organisations that must manage such a large group of people that are all at the same age and stage on an annual basis.

This annual cycle is driven by the business model used by Professional Services. This results in a structure that is bottom-heavy with a large pool of young people toward the bottom of the organisational hierarchy and older people, of a different generation, at the middle and the top of the organisation. The model is driven by large annual recruitment drives through tertiary institutions. "Year groups (Note 1)" tend to advance through professional Services Firms on a yearly basis as a mostly uniform group.

This results in hiring graduates from diverse backgrounds, that are intelligent and are career focused. They also have one more thing in common, their age and therefore their generation, namely Generation Y. The volume of Generation Y employees in any one year across the Professional Services industry is significant. This provides added weight regarding the impact of Generation $Y$ values on the workplace.

\section{Generation $Y$}

Current literature regarding Generation Y emphasises the following personal values (Sheehan, 2005; Kelan 2009):

- A focus on their development

- A focus on customising their careers

- A need to be independent

- Aselfishperspective

- A need to feel connected to the decision making process in their workplace

Anecdotal observations of Generation Y valuesin the workplace have included:

- A group mentality, taking a view as a year group on particular issues

- Comparisons against peers to establish personal opinions on performance, salary etc

- Open sharing of private data (performance, salary or otherwise)

- Inability to respond maturely to the data that has been shared

- Reaching a conclusion as a group based on non-factual data, this conclusion is then internalised

- Displeasure at not being consulted on decisions that are outside their sphere of influence

\section{The Groupthink Model}

Several theories are investigated in this article to try and explain the issue of "how Generation $\mathrm{Y}$ forms expectations and perceptions in relation to workplace rules and norms in a Professional Services Environment". Personality based theories, such as; Rotter's Locus of Control (1954), self-efficacy (Bandura, 1986), attraction theory, implicit personality theory, equity theory and social exchange theory were considered. All these theories were found lacking as it was implausible that the same personality based behaviours would exist across the an entire year group. 
Therefore group-related social theories were considered as possibilities for explaining how Generation Y; a smart, educated, confident group of individuals, could develop and internalise a shared set of perceptions and expectations regarding particular situations they encounter at work.

Janis' (1972) Groupthink theory was a highly comparable match in terms of explaining observed behaviour in "year groups". Groupthink describes how in-group pressures lead to a deterioration in decision making and a failure to appraise alternative courses of action as a result of striving for unanimity (Janis, 1982). The result of this process is the exertion of enough peer pressure or fear of being seen as 'different' from the group to encourage members of the group to suppress dissenting opinions and then rationalise the group's opinions as their own.

There has been much research into the Groupthink Model (Figure 1), with some research declaring the model inconclusive and others declaring that parts of the model have been verified (Rose, 2011). Irrespective of these studies Groupthink has established itself has a recognised theory and has been used constantly since its publication in the 1970's because the theory has an inherent level of plausibility (Baron, 2005).

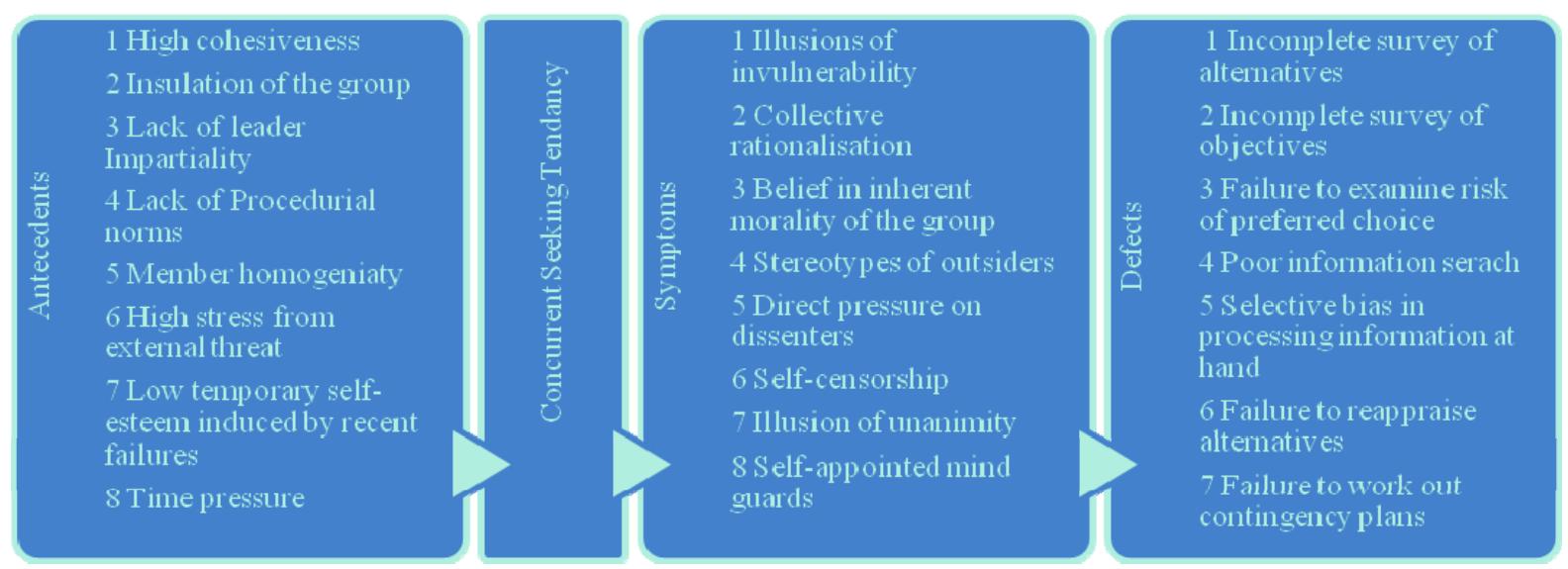

Figure 1. Groupthink model as outlined by Janis in 1982

As expected, various scholarly recommendations have been made regarding the Groupthink Model. Relevant variations are discussed later in this article, specifically those described by Baron (2005) as they propose a new set of Antecedents, if present, will encourage Groupthink to occur in almost every group interaction where consensus decisions are desired.

The aim is to demonstrate the applicability of the model to Generation Y decision making in the Professional Services industry. Each of the three components of the Model (Figure 1) will be discussed, evaluated and applied to this situation. The intention is to present an emended Groupthink Model with a greater level of applicability to the anecdotal behaviour observed in Generation $Y$ year groups.

\subsection{Antecedents}

Antecedents underpin the Groupthink theory as without these 'prerequisites' Groupthink will not occur. The Antecedents are among the most empirically tested aspects of the Groupthink theory (Rose, 2011). A number of studies have delivered various results. Only two of the prescribed Antecedents prescribed by Janis (1982) consistently show a correlation with the occurrence of Groupthink, these are; lack of leader impartiality (Rose, 2011) and member homogeneity (Baron, 2005).

Baron (2005) has proposed the use of three alternative Antecedents that would facilitate the application of Groupthink ubiquitously. The intention is to combine these three Antecedents with the empirically tested Antecedents above as they seem highly relevant to the environment and context (Generation Y and Professional Services). The following is the justification for integrating each of Baron's (2005) Antecedents into the Groupthink Model.

Baron's (2005) three Antecedents are; social identification, salient norms and low self efficacy. Social identification is similar to the empirically tested prescribed Antecedents; member homogeneity. So for the purposes of this article social identification will include member homogeneity. This means four Antecedents will be discussed and applied to Generation Y employees in Professional Services Firms; social identification, salient norms, low self efficacy and lack of leader impartiality. 


\subsubsection{Social Identification}

Social identification is the degree to which there is a sense of identification between group members. The degree of entitativity (Campbell, 1958) within the group is dependent on the extent to which the members have had shared experiences in the past or similar aspirations in the future (Campbell, 1958, Hamilton \& Sherman, 1996). Baron (2005) explains quite thoroughly how the presence of social identification contributes to the process of Groupthink though the expression of 'in-group' preferences (regarding information sources), distrust of outsiders, amplification of normative social influence and application of classical conditioning.

Professional Services Firms introduce a significant number of new employees into the firm on a yearly basis through their graduate recruitment processes. Almost all of whom are; of a similar age, have existing personal connections (physical or via social media) that they bring with them from university, have similar career aspirations, are well educated, are high performing, have a focus on social media, inducted in a similar manner into the industry and are part of Generation Y. It would be reasonable to state that the degree of social identification will be high. Social identification with these likeminded people is then reinforced by the need to remain 'in-group'. This is achieved by using sociological concepts such as; amplified normative social influence, punishment and deviance from normal behaviour. In an year group environment the desire to remain 'in-group' is strong. Staying 'in-group' is a high motivator to adjust the expression of dissenting opinions, thoughts and feelings to the group (amplified normative social influence). This is compounded by the threat of banishment from the group (punishment in the form of additional social anxiety) if dissenting opinions are expressed (deviance from the norm).

\subsubsection{Salient Norms}

Salient norms are the 'hidden' patterns of social behaviour that are observed in groups of people. In the context of Groupthink "interaction and discussion must produce or reveal an emerging or dominant group norm if the Symptoms and defective decision process or Groupthink are to occur" (Baron, 2005). The salient norms of an annual 'intake' of Generation Y employees are their values. There are many sources of information on Generation Y values. However an empirically based report published in 2008 by Robert Half International and another empirically based report published by PWC (Price Waterhouse Coopers) in 2012 will be used as the main source of data as they touch on most of the areas mentioned in various other publications. These sources identified the following as significant values for Generation Y:

- being technologically literate which translates to time spent online and invested in social media

- a constant need for developmental feedback

- $\quad$ an expectation to rise up the professional ranks quickly

- a desirable salary is very important

- a flexible working environment

- to have a meaningful say in any decision making process

- the ability to make new social connections and work with new and existing connections

It is reasonable to conclude that an intake of a group of people of a similar age and stage in their career, that have also come from similar backgrounds would greatly increase the possibility of shared values being held by the group. Anecdotally, the values outlined above are widely observed in Generation Y employees indicating the presence of salient norms in the workplace. Just as with the social identification criteria there is a negative reinforcing aspect. Individuals within the group with opposing values or opinions will be disenfranchised as pre-existing or emergent norms bias the discussion thus discouraging further dissenting remarks from those individuals (Baron, 2005).

\subsubsection{Low Self-Efficacy}

The final of Baron's (2005) Antecedents is low self-efficacy. Self efficacy as defined by Bandura (1986) as people's beliefs about their capabilities to produce effects. Self efficacy is different to self esteem (a person's overall sense of self-worth or personal value). Bandura (1986) used the following example to show the difference; an individual may have low self-efficacy for ballroom dancing [his belief in his own ability], but if ballroom dancing is not very important to that individual, this is unlikely to result in low self-esteem. According to Baron (2005) the presence of low self efficacy in this context is predicated on the members within the group believing that their chances for solving the specific problem at hand are already diminished due to; fatigue, ability to influence, decision complexity, low self confidence, priming and negative social feedback. If this situation exists group members will be unwilling to offer dissenting opinions to that of the group. An individual 
would have to be extremely self confident to challenge the group and risk sanction e.g. in this case, exclusion from the year group, the individual's main source of confidence, support and friendship within a Professional Services Firm. Therefore, as with salient norms and social identification there is a negative reinforcing aspect, opinions that challenge group norms may result in an individual being outcast from the group.

The annual 'intake' of new employees within a Professional Services Firm are at the 'bottom' of the organisational pyramid, they very quickly discover that they have a lot to learn and this can lead to lower self efficacy levels. They have also not developed influential relationships, they have been primed (unintentionally) to not question Partners and Managers in Professional Services Firms, and there are a large number of them in the exact same situation. It is reasonable to conclude that when this group is faced with a problem they might:

- have low self confidence regarding influencing Partners to change a decision that negatively affects them

- get instant pressure from the group to 'band together' to solve the issue as they are all in the same year group and are treated similarly

- not have the confidence to offer counter opinions to those held by the year group

When these points are taken into account there is a strong motivator for employees within the group to not dissent against opinions held by the majority of the group and to internalise the groups' decision.

\subsubsection{Lack of Leader Impartiality}

The final Antecedent is lack of leader impartiality, one of Janis' (1982) original set. Lack of leader impartiality is where a leader of a group uses their influence or power to promote a certain outcome regarding a particular situation. Rose (2011) concludes that lack of leadership impartiality leads to Groupthink as there are many studies that have shown leaders who engage in constructive searches for alternative options frequently produce better outcomes (Fodor \& Smith, 1982; Flowers, 1977; Leana, 1985).

There is no available research into leadership amongst Generation Y year groups in Professional Services Firms. However there is a large amount of research regarding the soliciting of personal networks to make decisions and the existence of informal leaders within these networks. Personal networks form within organisations, people within personal networks have more influence on each other than members from other networks (Kleiner, 2003). These networks also help fulfil the psychological needs of those involved i.e. support, guidance etc (McDermott and O'Dell, 2001; Maslow and Toward, 1962).

Opinion leaders exist within personal networks. They become powerful because they have social capital (Smith, 2005). Social capital is defined as "The set of resources, tangible or virtual, that accrue to a corporate player through the player's social relationships, facilitating the attainment of goals" (Gabbay \& Leenders, 1999). They may also have achieved legitimacy though intellectual grunt, awareness of situations, emotional resilience and personal drive. This results in opinion leaders possessing strong influencing skills, astuteness, insight, judgments and the ability to identify more alternative actions. This means that they can better navigate complex and dynamic organizational realities and influence effectively within them (Butcher et al., 1997).

Opinion leaders are identifiable in groups/networks because they have higher levels of prestige or influence with their peers, they form "core groups" and their names come up time and again in their peers' hearts, minds and stories, not because they have authority but because they have attained legitimacy (Kleiner, 2003). They have attained legitimacy or informal power (influence) within the workplace by drawing on several differing power bases. These are (Baron \& Greenberg, 1997):

- Informational power - the extent to which one has access to information that others do not

- Personal power - the power that one derives because of their individual qualities or characteristics

- Rational persuasion - the ability to use logical arguments to convince others than an approach is acceptable

- Exert power - the individual power base derived from an individual's recognised superior competency

- $\quad$ Referent power - the individual power base derived from the degree to which they are is liked and admired by others

All of the above organisational dynamics and personal traits are to be found in Professional Services Firms and employees of Professional Services Firms. It is reasonable to conclude the following:

- Networks exist amongst Generation Y year groups in Professional Services Firms

- Personal networks have more influence than other networks for Generation Y year groups

- Opinion leaders exist with these personal networks 
- These opinion leaders can utilise the above mentioned types of power bases available to them

Once again a negative reinforcing behaviour exists as while an informal leader may not be able to punish other members, a characteristic outlined by Baron (2005), they will still have enough informal or social power to ostracise dissenters.

The above application of the four Antecedents to Generation Y in a Professional Services Firm demonstrates that there is a basis for Groupthink to occur.

\subsection{Symptoms and Defects of Groupthink}

The anecdotal evidence mentioned throughout the article regarding Generation $Y$ behaviours are reflective of the Symptoms and Defect components of the Groupthink Model. The Symptoms are the behaviours that will be observed within a group that is using Groupthink. The Symptoms are divided into three categories (Janis, 1982):

- Overestimation of the groups abilities

a Illusions of invulnerability

b Belief in the inherent morality of the group

- Closed mindedness

c Collective rationalisation

d Stereotypes of outsiders

- Pressure toward uniformity

e Direct pressure on dissenters

f Self-censorship

$\mathrm{g} \quad$ Illusion of unanimity

h Self-appointed mind guards

After several years of Generation Y year groups passed through Professional Services Firms, it became apparent that certain behaviours were beginning to become common place. The reasons for the behaviour have baffled line managers and human resource staff for some time. Hence the need to find a model that explained the behaviour and therefore provided some strategies to change that behaviour.

A number of the behaviours observed fit well with the Symptoms of Groupthink. A selection of observed examples and their associated Groupthink Symptom are outlined in Figure 2.

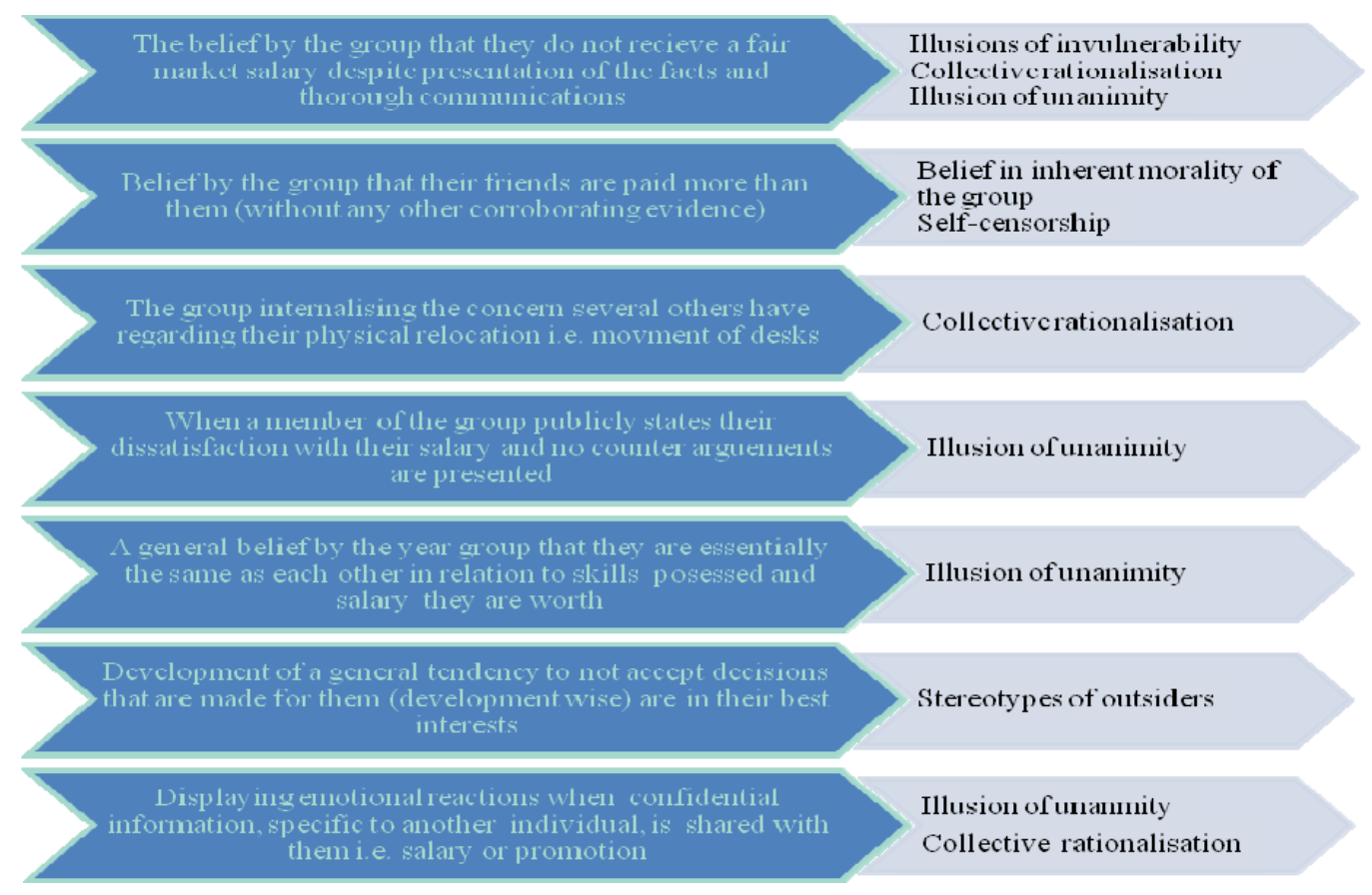

Figure 2. Selection of observed behaviours and their associated groupthink symptoms 
Based on these observations all the Symptoms except H (Self-appointed mind guards) are applicable to applying the Groupthink Model to Generation Y in the workplace.

The same can be said for the Defects of Groupthink. The Defects of Groupthink are the outcomes of the Groupthink process. Janis (1972) outlined seven Defects:

- Incomplete survey of alternatives

- Incomplete survey of objectives

- Failure to examine risk of preferred choice

- Poor information search

- Selective bias in processing information at hand

- Failure to reappraise alternative

- $\quad$ Failure to work out contingency plans

A number of the arguments put forward by Generation $Y$ to management in relation to workplace decisions and rules were not thoroughly thought through and showed a lack of consideration for the longer term implications outcomes. A selection of examples along with associated Groupthink Defects are outlined in Figure3.

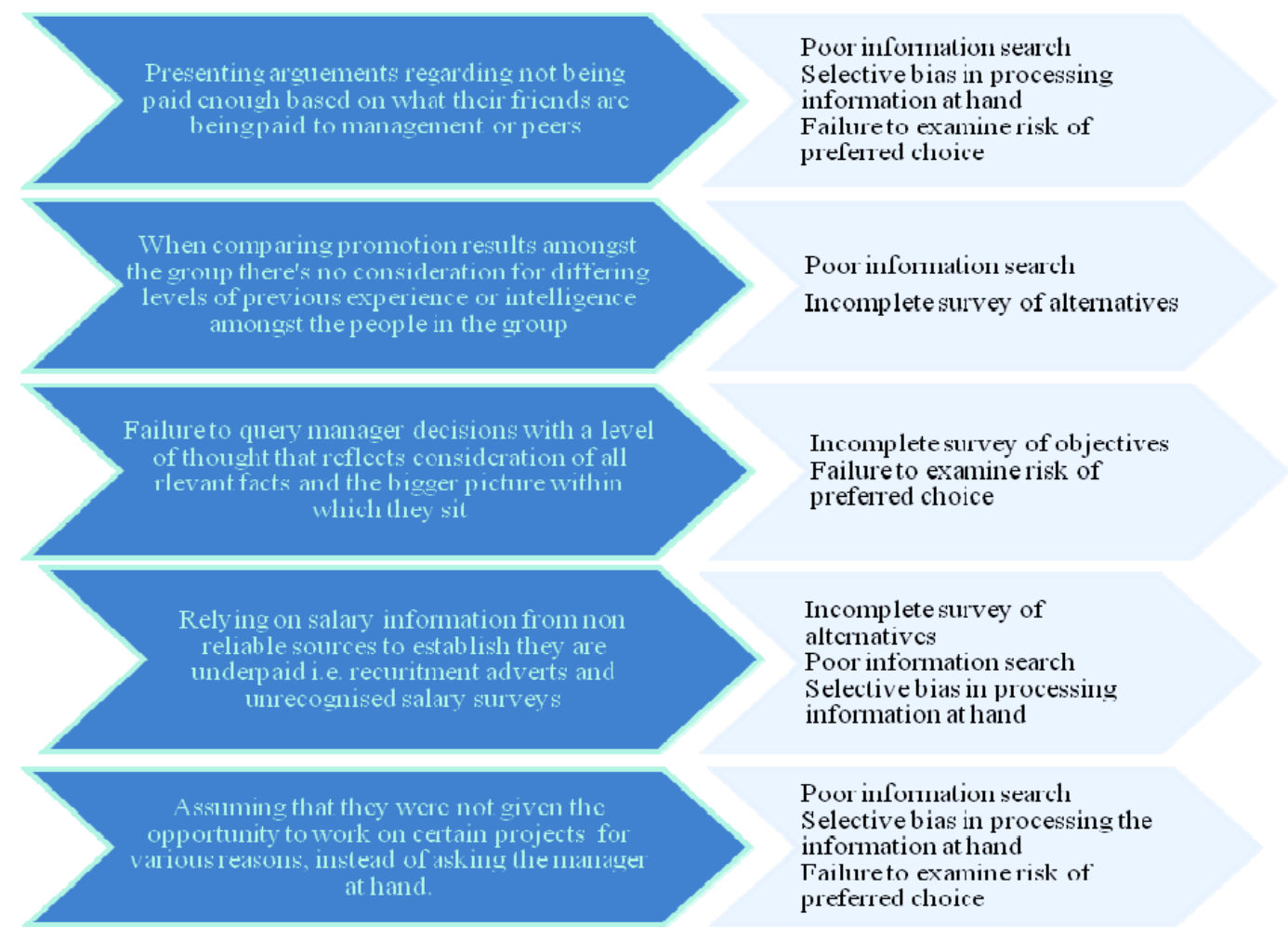

Figure 3. A selection of observed behaviours along with associated groupthink defects

Based on these observations all the Symptoms except 'failure to work out contingency plans' and 'failure to reappraise alternative' are not applicable.

From the above observed behaviours of Generation Y in Professional Services Firms and their alignment with the Groupthink Symptoms and Defects it is reasonable to conclude that the Groupthink Model is considered to be the most appropriate model for explaining the decision making process used by Generation $\mathrm{Y}$ to form expectations and perceptions in relation to workplace rules and norms.

\section{Lessons for Organisations}

The intention of the article was to apply a theory to explain the decision making process used by Generation $\mathrm{Y}$ to form expectations and perceptions in relation to workplace rules and norms in a Professional Services 
environment. Once explained the hope was that a range of actions could be put forward that would provide a starting place for changing the behaviour of Generation Y.

When Janis (1982) proposed the Groupthink Model he also outlined nine actions that could be taken to prevent Groupthink from happening. Janis' (1982) prevention steps have been integrated with a study by Chen et al. (2009) to produce five viable operationalised options that are conducive to producing an environment that reduced the chances of Groupthink occurring given the informal nature of the group's formation.

1) Educating leaders within the group to be 'better leaders' by encouraging them to be impartial when discussing problems at hand and not stating their expectations up front.

2) Dividing the group as much as possible to create opportunities for sub groups to develop their own opinions. Division could be achieved by increasing the specialisation of workloads or physically arranging people in the workplace.

3) Introduce trusted associates or experts from other parts of the business into the group to challenge the group to consider alternative options to the problem at hand.

4) Once the group has come to an outcome regarding the situation, give them a second change to speak to certain other people or revaluate their position.

5) Encourage clear and safe communication channels with management to cater for challenging discussions.

There are four further preventative measures that can be considered that are not mentioned or tested in the Groupthink literature. There are strategies used to promote culture change that are able to be applied to Generation Y decision making processes in professional Service Firms.

1) The strengthening of the direct report relationship results in the development of trust in a relationship which can be leveraged to encourage employees to consider other factors during their personal decision making process (Corporate Leadership Council, 2004).

2) Educating the workforce regarding the wider environment within which the business operates and how all the associated components will help generation of alternative solutions to the problem at hand (Baron \& Greenberg, 1997).

3) The creation of confidential communication avenues so people with dissenting opinions have a form of support to build their confidence so they are more likely to voice alternative solutions (Carter et al., 2001).

4) When addressing groups a focus on the 'what's in it for me' factor moves people out of a defensive state so they are more open to entertain alternative outcomes (Carter et al., 2001).

5) Legitimising the informal network i.e. making it a formal part of decision making or formally trying to influence opinion leaders within the network. It is a common theme amongst successful companies that informal networks are leveraged to help the company achieve its greater goals (McDermott \& O’Dell, 2001).

\section{Conclusion}

In any everyday workplace environment, especially a Professional Services environment with annual graduate intakes, experiences are quickly internalised into beliefs and opinions (Smith, 2005) and once formed, are difficult to change (Smith \& Saint-Onge, 1996; Argyris, 1991). It is reasonable to conclude that the Groupthink Model with the emendations outlined in this article (Figure 4), is a viable model to explain and predict the behaviour of Generation Y in a Professional Service Firm environment.

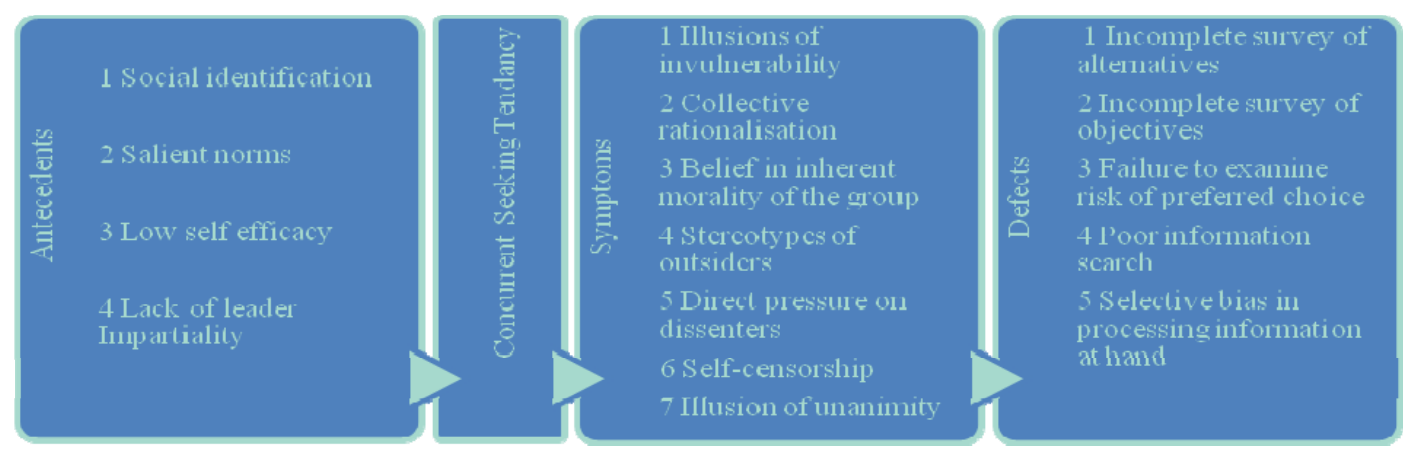

Figure 4. Recommended Groupthink model to explain decision making processes in Generation Y employees within professional services firms 
Knowing the root of the behaviours expressed by Generation Y, organisation's should be able to better educate and influence Generation Y regarding their career choices and conduct within the workplace. There are many positive aspects to Generation Y's presence in the work place, this should not be forgotten.

\section{References}

Argyris, C. (1991). Teaching smart people how to learn. Harvard Business Review, May-June, 99-109.

Bandura, A. (1986). Social Foundations of Thought and Action: A Social Cognitive Theory. Englewood Cliffs, NJ: Prentice-Hall.

Baron, R. (2005). So Right It's Wrong: Groupthink and the Ubiquitous Nature of Polarized Group Decision Making. Advances in Experimental Social Psychology, 37, 219-253. http://dx.doi.org/10.1016/S0065-2601(05)37004-3

Baron, R., \& Greenberg, J. (1997). Behaviour in organisations. Upper Saddle River, NJ: Prentice-Hall.

Butcher, D., Harvey, P., \& Atkinson, S. (1997). Developing business through developing individuals. Cranfield School of Management, Cranfield University, Cranfield.

Campbell, D. T. (1958). Common fate, similarity and other indices of the status of aggregates of persons as social entities. Behavioral Science, 3, 14-25. http://dx.doi.org/10.1002/bs.3830030103

Carter, L., Giber, D., \& Goldsmith, M. (2001). Best practice in organisational development and change. San Francisco: Jossey-Bass/Pfeiffer.

Chen, C., Cheng-Ho, T., \& Kuo-Chin, S. (2009). An exploratory study for Groupthink research to enhance group decision quality. Journal or Quality, 16(2), 137-152.

Corporate Leadership Council. (2004). The hourly manager: strategies for increasing frontline managers' people development effectiveness. Retrieved from https://clc.executiveboard.com

Eisner, S. P. (2005). Managing Generation Y. SAM Advanced Management Journal, 70(4), 4-15.

Flowers, M. L. (1977). A laboratory test of some implications of Janis's groupthink hypothesis. Journal of Personality and Social Psychology, 35, 888-896. http://dx.doi.org/10.1037/0022-3514.35.12.888

Fodor, E. M., \& Smith, T. (1982). The power motive as an influence on group decision-making. Journal of Personality and Social Psychology, 42, 178-185. http://dx.doi.org/10.1037/0022-3514.42.1.178

Gabbay, S., \& Leenders, R. (1999). The structure of advantage and disadvantage. In Leenders, J., \& Gabbay, S. (Eds.), Corporate Social Capital and Liability. Boston, MA: Kluwer Academic Publishers. http://dx.doi.org/10.1007/978-1-4615-5027-3_1

Hamilton, D. L., \& Sherman, S. J. (1996). Perceiving persons and groups. Psychological Review, 103, 336-355. http://dx.doi.org/10.1037/0033-295X.103.2.336

Janis, I. L. (1972). Victims of groupthink. Boston, MA: Houghton Mifflin.

Janis, I. L. (1982). Groupthink: Psychological studies of policy decisions and fiascos (2nd ed.). Boston, MA: Houghton Mifflin.

Kelan, E. (2009). The Reflective Generation: Young professionals' perspectives on work, career and gender. London Business School.

Kleiner, A. (2003). Core groups: a theory of power and influence for 'learning' organizations. Journal of Organizational Change Management, 16(6), 666-683. http://dx.doi.org/10.1108/09534810310502595

Leana, C. R. (1985). A partial test of Janis' Groupthink Model: Effects of group cohesiveness and leader behavior on defective decision-making. Journal of Management, 11, 5-17. http://dx.doi.org/10.1177/014920638501100102

Loew, D., Levitt, J., \& Wilson, T. (2008). Solutions for Retaining Generation Y Employees in the Workplace. Business Renaissance Quarterly, 3(3), 43-57.

Maslow, A., \& Toward, A. (1962). Psychology of Being. Princeton, NJ: Van Nostrand. http://dx.doi.org/10.1037/10793-000

McDermott, R., \& O’Dell, C. (2001). Overcoming cultural barriers to sharing knowledge. Journal of Knowledge Management, 5(1), 76-85. http://dx.doi.org/10.1108/13673270110384428

Millennial at work: Reshaping the workplace. (2012). UK: Price Waterhouse Coopers. Retrieved from 
http://www.pwc.com/gx/en/managing-tomorrows-people/future-of-work/download.jhtml

Rose, J. (2011). Diverse Perspectives on the Groupthink Theory. Emerging Leadership Journeys, 4(1), 37-57.

Rotter, J. B. (1954). Social Learning and Clinical Psychology. Englewood Cliffs, NJ: Prentice-Hall. http://dx.doi.org/10.1037/10788-000

Sheahan, P. (2005). Generation Y. Australia: Hardie Grant Books.

Smith, P. A. C. (2005). Knowledge sharing and strategic capital - The importance and identification of opinion leaders. The Learning Organization, 12(6), 563-574. http://dx.doi.org/10.1108/09696470510626766

Smith, P. A. C., \& Saint-Onge, H. (1996). The evolutionary organization: avoiding a Titanic fate. Retrieved from http://www.tlainc.com/TLO\%20V3\%20N4\%2096.pdf

Yahoo Hot Jobs/Robert Half International. (2008). What Millennial Workers Want: How to attract and retain Gen Y employees. Menlo Park, CA: HRI - Robert Half International.

\section{Note}

Note 1. Year Groups are a common term within Professional Services Firms that refer to a specific year of annual intake of employees. Year groups will usually be trained together and experience career milestones i.e. promotion, at approximately the same time. 